\title{
Early measure of postoperative iPTH and corrected calcium as predictors of future hypoparathyroidism: Which, when and why?
}

\author{
M. Paja, C. Moreno, E. Ugarte, A. Oleaga, ${ }^{1}$ MT. Gutiérrez, AJ. Izuzquiza, E. Etxeberría, N.C. Iglesias, A. Lizarraga,
}

2 M.P. Martínez-Mate.

\section{Endocrinology, ${ }^{1}$ Endocrine Surgery, Hospital de Basurto}

2Biochemistry . Bibao, Spain

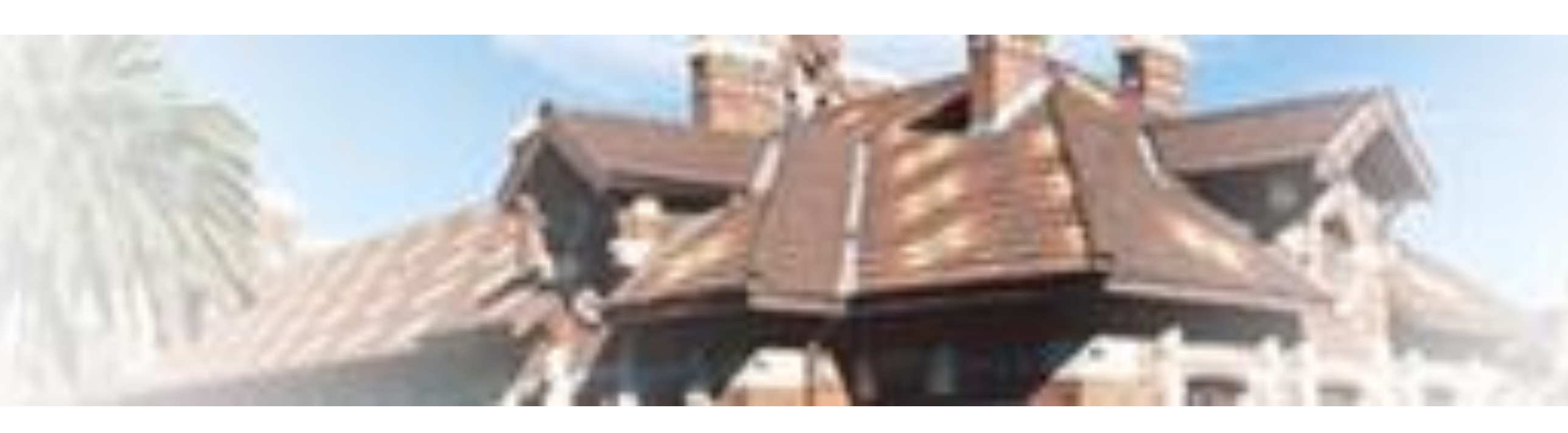

Intraoperative parathyroid hormone assay (ioPTH) has been validated as a useful tool predicting postoperative hypocalcemia after thyroid surgery and has been proposed as a guide to early discharge from hospital. Its value to predict risk of future hypoparathyroidism (hypoPT) has not been studied in detail. We evaluate this aspect in our recent surgical series.

Material and methods - We include 748 patients who underwent total thyroidectomy from 2005 to 2011 . They were evaluated more than one year after surgery. Permanent hypoPT (PhypoPT) is defined by [iPTH] $<15 \mathrm{pg} / \mathrm{ml}$ without treatment one year passed after surgery. [iPTH] between $5-15 \mathrm{pg} / \mathrm{ml}$ were defined as partial deficiency, whereas less than $5 \mathrm{pg} / \mathrm{ml}$ were considered total deficiency. Cases with spontaneous recovering of parathyroid function after a period of $[\mathrm{iPTH}]<15$ were named as transient hypoPT (ThypoPT). We analyze the correlation between [iPTH] measured 24 hours after surgery, [iPTH24h], and future parathyroid function. We also analyze the correlation between [iPTH] measured immediately, 1 to 3 hours after surgery, [iPTH1-3h], corrected calcium monitored 6 hours postoperatively [Ca6h], and subsequent parathyroid status.

Results - 502 patients had measurements of [iPTH24h], 305 of them also had previous [iPTH1-3h]. Globally, 377 patients never showed $[\mathrm{iPTH}]<15 \mathrm{pg} / \mathrm{ml}$. Forty of the remainder (125) suffered from PhypoPT, half of them total deficiencies $(>5)$, and 85 transient forms, resolved in the first month after surgery in $56 \%$ of them.

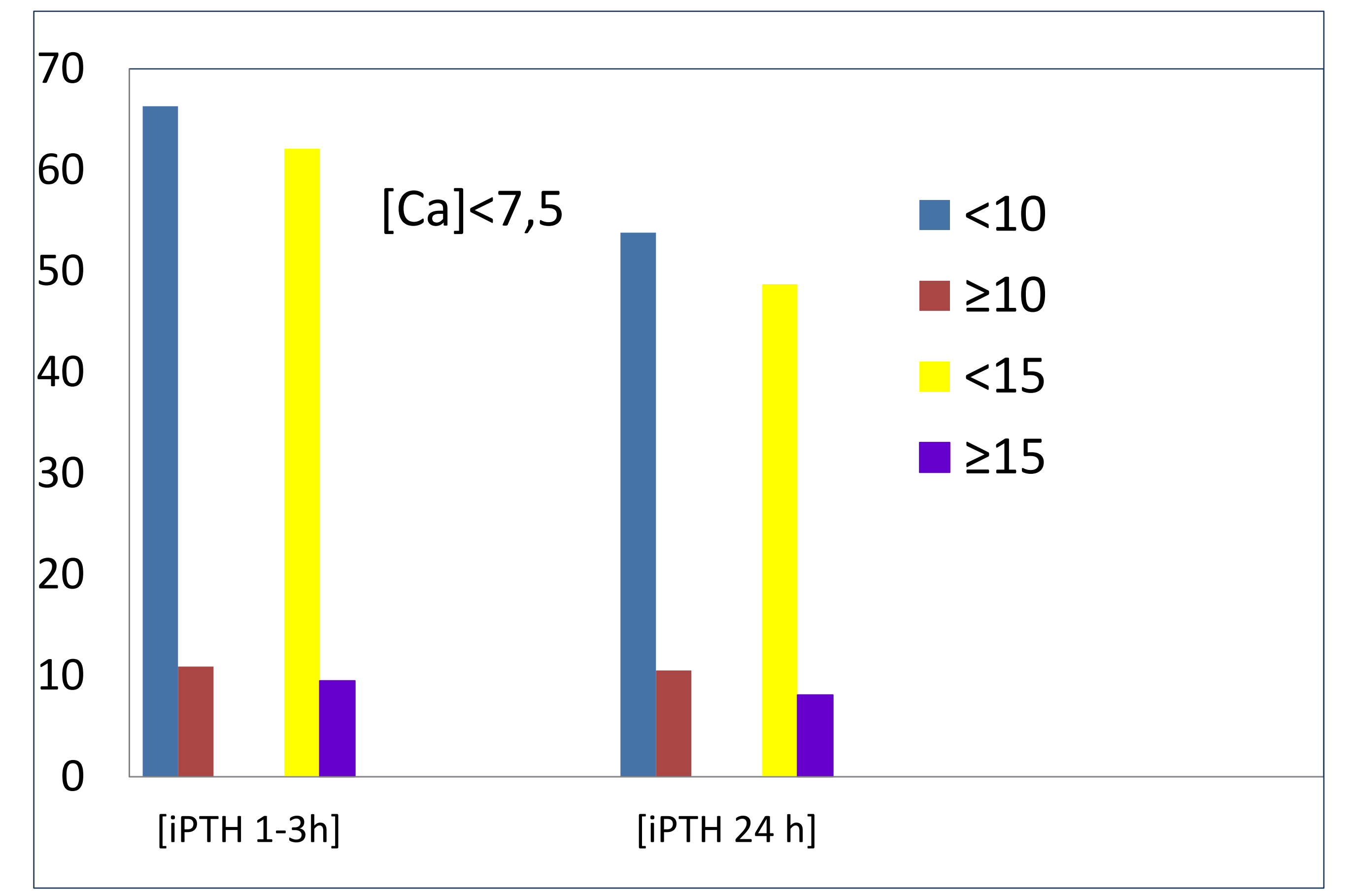

\begin{tabular}{|l|c|c|c|c|c|}
\hline & No hypoPT & $\begin{array}{c}\text { Permanent } \\
\text { hypoPT }\end{array}$ & $\begin{array}{c}\text { Transient } \\
\text { hypoPT }\end{array}$ & $\begin{array}{c}\text { All } \\
\text { hypoPT }\end{array}$ & $p^{*}$ \\
\hline $\mathrm{n}$ & 377 & 40 & 85 & 125 & \\
\hline [iPTH1-3h]] & $34.9(28)$ & $0.22(1.2)$ & $4.04(8.9)$ & $3.1(7.9)$ & $<.001$ \\
\hline [iPTH24h] & $39.1(23.5)$ & $0.87(2.5)$ & $4.44(8.3)$ & $3.54(3.5)$ & $<.001$ \\
\hline [Ca6h] & $8.63(0.49)$ & $8.18(0.57)$ & $8.24(0.66)$ & $8.22(0,64)$ & $<0,001$ \\
\hline
\end{tabular}

TABLE - Mean (SD) and [range] of the 3 parameters: both iPTH and calcium. *p: statistical signification between "No HypoPT" and "All hypoPT".

\begin{abstract}
Postoperative hypocalcemia, defined as corrected plasmatic calcium $<7,5 \mathrm{mg} / \mathrm{dl}$, presented in 183 of 647 patients (24,5\%); in $66.3 \%$ of patients with [iPTH24h] $<10 \mathrm{pg} / \mathrm{ml}$, vs $10.9 \%$ of them with [iPTH24h] $\geq 10 \mathrm{pg} / \mathrm{ml}$ (OR: 3.48 [IC:2,6-4,64]. The OR for postoperative hypocalcaemia with [iPTH1-3h] $<10 \mathrm{pg} / \mathrm{ml}$ was 3,89 [IC: 2,48 - 6.10]. These ORs were 4,08[IC:2.93-5.68] and 4.57[IC:2.68-7.81] when considering a limit of $15 \mathrm{pg} / \mathrm{ml}$. [iPTH24h] $>15 \mathrm{pg} / \mathrm{ml}$ was present in $5 \%$ of patients with hypoPTH and [iPTH1-3h] $>15 \mathrm{pg} / \mathrm{ml}$ in $9.5 \%$, all ThypoPT. Mean [Ca6h] was significatively different between patients who suffer hypoPT and not $(8,63$ vs $8.22 ; p<0.001)$.
\end{abstract}

Conclusions - Our series, as others published, confirms usefulness of perioperative [PTH] as predictor of postoperative hypocalcemia and future hypoPT, but we don't find an exact level or timing for its measurement. 